\title{
LEITURA EM REDE
}

\author{
CANOAS/RS JULHO/2018
}

\begin{abstract}
ANGELA DA ROCHA ROLLA - ULBRA - arolla@terra.com.br
\end{abstract}
Tipo: Relato de Experiência Inovadora (EI)

Categoria: Métodos e Tecnologias

Setor Educacional: EDUCAÇÃO INFANTIL E FUNDAMENTAL, EDUCAÇÃO SUPERIOR

\begin{abstract}
RESUMO
LEITURA EM REDE é um programa de leitura que se propõe a estabelecer uma rede de comunicação (virtual e presencial) de acadêmicos extensionistas com mediadores de leitura, escritores, ilustradores, poetas, músicos, atores e jovens leitores brasileiros nos municípios de abrangência do EAD da ULBRA. Estrutura-se através da plataforma da universidade, em módulos independentes, com duração de um ano, tendo como foco um escritor brasileiro e suas obras em vários suportes/mídias. $O$ escritor de 2017/2018 é o escritor, tradutor, editor, ativista, intelectual em ação, José Bento Renato Monteiro Lobato. Focando no autor, o percurso deste projeto extensionista envolve vários mediadores: inicia com o acadêmico dos cursos EAD da universidade, o protagonista principal, buscando na sua comunidade próxima os mediadores de leitura (educadores, promotores culturais, agentes comunitários) e seus interlocutores (alunos, expectadores, usuários). O público-alvo mediador são estudantes e profissionais da área da literatura, da comunicação, da educação, da saúde, do entretenimento, da tecnologia e de outras áreas que trabalham com linguagens verbais e não verbais ou com ênfase no texto literário para o público infantil, juvenil e adulto em vários suportes. A meta mais importante do projeto é a formação de crianças, adolescentes e adultos leitores, contribuindo para a difusão de aspectos regionais da cultura brasileira e para o aumento do índice de letramento nos municípios em que atua. Programa de leitura virtual pioneiro no país, Leitura em rede integra a universidade às produções culturais das comunidades envolvidas, agregando a autenticidade da criação literária de Monteiro Lobato ao mundo hiperconectado da juventude contemporânea.
\end{abstract}

Palavras-chave: EAD, literatura, Monteiro Lobato 


\section{INTRODUÇÃO}

Leitura em rede é um desdobramento do Programa de Leitura Fome de Ler, com maior abrangência espacial e temporal. Estruturado como um projeto extensionista com acadêmicos da universidade de polos do EAD ou com público externo, o programa propõe-se a estabelecer uma rede de comunicação (virtual e presencial) entre escritores, ilustradores, acadêmicos, mediadores de leitura e leitores. O foco é a produção literária em vários suportes, utilizando-se de recursos da mídia digital para desenvolver e fomentar políticas de leitura nos municípios de abrangência do EAD da Universidade Luterana do Brasil em todo o território nacional. O programa abrange um espaço mais amplo do que o espaço escolar, buscando modos de ler não formais e/ou espaços virtuais.

Estrutura-se através da plataforma da Ulbra com duração de um ano, tendo como foco um escritor brasileiro e suas obras em vários suportes/mídias. O escritor de 2017/2018 é Monteiro Lobato. O autor, nacionalmente conhecido por sua obra literária e seu projeto de leitura para a criança brasileira, perpetua-se através de suas personagens, em especial Emília e Jeca Tatu.

O percurso do Programa envolve vários mediadores: inicia com o acadêmico dos cursos EAD da Universidade, o protagonista principal, buscando na sua comunidade próxima os mediadores de leitura (educadores, promotores culturais, agentes comunitários) e seus interlocutores (alunos, expectadores, usuários). O público-alvo mediador são estudantes e profissionais da área da literatura, da comunicação, da educação, da saúde, do entretenimento, da tecnologia e de outras áreas que trabalham com linguagens verbais e não verbais ou com ênfase no texto literário para o público juvenil e adulto. A meta mais importante do projeto é a formação de crianças, adolescentes e adultos leitores, contribuindo para a difusão de aspectos regionais da cultura brasileira e para o aumento do índice de letramento nos municípios em que atua.

\section{REFERENCIAL TEÓRICO}

A leitura é uma atividade humana que consiste em atribuir sentido às mais diversas formas de manifestação do homem e da natureza. É um processo de apreensão de significados, do qual o leitor participa ativamente a partir do diálogo que estabelece com o objeto lido, conforme suas experiências existenciais. Toda a sociedade, nas suas diferentes etapas evolutivas, produz uma memória cultural e a leitura vem a ser um dos instrumentos para conhecimento e transformação dessa memória, isto é, das ideias, instrumentos e técnicas produzidos e conservados pelo homem. Por isso mesmo, o 
processo de leitura apresenta-se como uma atividade que possibilita a participação do homem na vida em sociedade, em termos de compreensão do presente e do passado e em termos de transformação cultural futura.

Por constituir-se instrumento de aquisição e transformação do conhecimento, a leitura, quando crítica e reflexiva, levanta-se como um trabalho de combate à alienação, permitindo um caminho para a liberdade humana. No entanto, a leitura e a circulação da cultura estão marcadas pela exclusão e pelo fechamento. Por exclusão entende-se a negação absoluta desses bens e seu usufruto. Está excluída da leitura e da circulação da cultura - no sentido de discursos significantes - grande parte da população que não conta com situações favoráveis para leitura, nem com lugares propícios, nem com livros, nem com tempo suficiente, nem com uma mediação apropriada.

A escrita, segundo Foucambert,[1] é uma ferramenta de pensamento e comunicação que, por sua natureza, permite construir um modelo teórico a partir do real e expressar a coerência desse modelo inventando as relações entre os elementos. Nesse aspecto, o recurso à escrita, via produção de texto ou via leitura, é um momento essencial e específico de qualquer elaboração de um ponto de vista sobre o mundo, um meio de distanciamento e de teorização que permite passar do conjuntural, gerado pelo oral, ao estrutural, gerado pelo texto. Todo indivíduo que pretenda tomar poder sobre o mundo deverá lançar mão dessa forma de pensamento e, portanto, encontrar a escrita, independente do suporte onde se encontra.

Ser leitor significa, num determinado momento, estar integrado a redes de comunicação, sentir-se interlocutor da construção e do intercâmbio de pontos de vista sobre o mundo, exercer um comportamento social e práticas correspondentes a um estatuto e a condições específicas que se relacionam, ou até se conformam completamente, com a produção escrita tal como ela é.

Ser leitor significa participar de uma problemática inseparável de um posicionamento no mundo e sobre ele tal como a escrita, em todas as suas formas, o teoriza. Exatamente nesse ponto entra em jogo o princípio de exclusão do não leitor, não em virtude de sua impossibilidade técnica, sua falta de interesse ou desejo de ler, mas porque ele não está implicado na experiência social, nas preocupações e nos modos de análise que geram a produção de escritos. Não existe nenhuma universalidade nessa produção, mas, ao contrário, a exata expressão de um ponto de vista que só parece universal, pois, sendo o nosso, não exige qualquer esforço para ser adotado. A todo momento, o número de leitores e número de atores sociais se superpõem. Assim, a democratização da leitura ou, se se quiser, o aumento maciço do número de indivíduos engajados em redes de 
comunicação escrita - inscreve-se precisamente nesta alternativa: ou os atuais excluídos assumem a maneira de ver, sentir, pensar da minoria que produz e consome a escrita, ou criam os novos escritos, correspondentes à sua abordagem do mundo, à sua experiência e ao poder que neles adquirem.

Nesse modo de ver (proposto inteligentemente por Foucambert na obra $A$ leitura em questão), a mediação dos educadores torna-se ainda mais complexa, pois somente a adoção de políticas de sedução do livro não contempla o grupo social que precisa ser incluído no circuito da leitura. Para esse grupo também se transformar em autor, outros deverão ser os protocolos, as formas de ler, os acervos, não bastando somente estarmos do lado de cá como sujeitos leitores e apropriados do mundo da escrita. As soluções e as mudanças de comportamento, então, não poderão vir do segmento letrado, sendo essencial a participação dos segmentos não letrados através da sua consciência do processo e vontade de vencer os entraves criados por uma sociedade excludente a partir da criação de novos/próprios modelos de ler e de escrever. A proposta de Leitura em rede, em sua abrangência virtual, poderá ampliar essas possibilidades alcançando leitores em diferentes espaços e realidades.

\section{PROCEDIMENTOS METODOLÓGICOS}

Leitura em rede envolve vários segmentos - orientador, acadêmico, mediador, interlocutores, especialistas - em uma rede de relações que culmina em projetos extensionistas realizados pelos acadêmicos/profissionais nos seus municípios.

$\mathrm{Na}$ primeira etapa, o acadêmico extensionista entra em contato com o material preparado para o projeto - sobre o escritor Monteiro Lobato- e interage com a professora orientadora e seus colegas através da NetAula. Nesta fase, as leituras e o acesso a vídeos, entrevistas, imagens são importantes, assim como a comunicação com seus pares para o aprimoramento do estudo. Pesquisas sobre o assunto fora da plataforma são realizadas, pois quanto mais o acadêmico se identificar com o tema que vai abordar, melhor será seu desempenho. O escritor brasileiro foi, no dizer de Maria Antonieta Cunha, "um intelectual em ação: nunca se contentou com só refletir, discutir e escrever; amava experimentar e arriscar-se, daí ter estado sempre em meio a empreendimentos (...) o que o fez estar no centro de várias polêmicas culturais e econômicas importantes de seu tempo".[2] 
$\mathrm{Na}$ segunda etapa, o acadêmico extensionista inicia a preparação do seu projeto de extensão e concomitantemente busca um mediador em sua comunidade para desenvolvê-lo. O projeto só será finalizado quando se concretizar a parceria do acadêmico extensionista com o mediador e seus interlocutores. Um dos critérios para a elaboração do projeto é o conhecimento da realidade onde ele será desenvolvido, através do contato real com o público escolhido (sejam eles educadores, promotores culturais, agentes comunitários etc) e o seu protagonismo em todo o processo.

Essa escolha - seja em uma escola, um clube, centro comunitário - é muito importante e decisiva para o sucesso dos projetos individuais. Os principais beneficiados do projeto são as crianças, adolescentes ou adultos que realizam a experiência com o autor. $O$ mediador escolhido deve estar envolvido com um público desta faixa etária. Toda esta etapa é partilhada na NetAula e acompanhada pela professora orientadora através da plataforma do projeto.

$\mathrm{Na}$ terceira etapa, a realização (presencial) da experiência é coordenada pelo acadêmico em seu município. Com o planejamento em mãos, o acadêmico realiza os trâmites legais (licença da direção da instituição para realização da experiência, de acordo com as regras desta instituição), organiza o cronograma e inicia o trabalho com a participação do mediador e de seus interlocutores. Com acompanhamento virtual da orientadora, o projeto é realizado na instituição escolhida buscando envolver a comunidade interna, externa e as atividades culturais do município. O tempo de duração pode ser de alguns meses, com encontros semanais, dentro das possibilidades do projeto e da interação com os envolvidos. O registro da experiência é então apresentado em vários suportes (relato escrito, foto, vídeo, gravação, audição, depoimento, entrevista, reportagem em jornal) que são compartilhados na plataforma virtual ou através de outras mídias.

\section{RESULTADOS E DISCUSSÃO}

Em 2017, em segunda edição, o projeto se desenvolveu com dez acadêmicos extensionistas da Universidade Luterana do Brasil, nos municípios de Canoas, Estância Velha, Gravatai, Nova Hartz, Sapiranga, São Jerônimo, Torres e Tramandaí, no Rio Grande do Sul e Diamante do Sul, no Paraná. A diversidade regional permitiu a realização de abordagens muito significativas para a obra do autor, valendo-se de recursos da virtualidade para a produção de leitores de Lobato na realidade. O projeto está em sua terceira edição, com a formação de um grupo de vinte e cinco acadêmicos extensionistas (público interno) e profissionais de fora da universidade ou pertencentes a polos da Ulbra do Rio Grande do Sul: Alvorada, Barra do Ribeiro, Cachoeirinha, 
Candelária, Canoas, Gravatai, Paverama, Porto Alegre, Rodeio Bonito, Salvador do Sul e Sapucaia do Sul. A expectativa é positiva para a formação de leitores de Lobato em razão da carência de muitos municípios e da qualidade da formação dos participantes do projeto: magistério; graduação, especialização e mestrado em Pedagogia e Letras; formação em Literatura e jogos digitais, Aprendizagem de leitura e escrita em ambiente virtual; docência em ensino fundamental e médio.

A diversidade cultural dos municípios citados agrega novas possibilidades ao estudo inicial, que vai depender em muito da familiaridade dos acadêmicos e dos outros envolvidos no projeto. Certamente, um paulista da região de Taubaté ou um estudante da cidade de São Paulo não terá o mesmo olhar para o universo de Lobato, sob o ponto de vista de suas origens. Não se fala aqui da obra lobateana, que é (ou foi) objeto de leitura de grande parte das crianças brasileiras do século XX. Trata-se da proximidade que os estudantes paulistas têm de conhecer "ao vivo" os sítios onde Lobato viveu a sua infância e o início de sua vida adulta, com esposa e filhos: Fazenda São José do Buquira, hoje Sítio do Picapau Amarelo, no Vale do Paraíba, próxima à cidade de Monteiro Lobato e Sítio do Picapau Amarelo, no município de Taubaté4[3]. A cidade de Taubaté se denomina "capital nacional da literatura infantil" e abriga um museu dedicado a Lobato, na casa do avô, Visconde de Tremembé, onde viveu sua infância.

O museu é uma casa antiga com pé-direito alto. Em uma das salas, logo na entrada, móveis e objetos que pertenceram à família do escritor. No ambiente seguinte, uma exposição iconográfica conta a trajetória de Lobato. $\mathrm{Na}$ cozinha, elementos antigos como chaleiras, pilões, moedores e fogão a lenha transportam a imaginação do visitante para um tempo em que Dona Benta serviria um bolo quentinho a seus netos. O espaço ainda abriga um teatro e uma biblioteca infantil com as obras de Monteiro Lobato. Há programação de oficinas de artes para o público infantil, brincadeiras, peças teatrais com os personagens imortalizados pelo autor e outras atividades disponíveis no site oficial do museu: www.museumonteirolobato.com.br

A valorização cultural (e até turística) dos escritores brasileiros a partir de seu lugar de nascimento, com poucas exceções, é algo quase inexistente em nosso país. Ao comparar com o investimento que a Dinamarca faz com seu maior escritor, Hans Christian Andersen, percebe-se a distância que ainda separa o Brasil em termos de valorização de seus ícones literários. Em Odense, na Dinamarca, a cidade inteira respira o espírito e as obras do escritor Hans Christian Andersen, seu filho pródigo. Na biblioteca do Museu dinamarquês, o visitante encontra um painel com os seus contos traduzidos em 125 idiomas. Não há como ficar indiferente: o museu e as homenagens estão em todo o lugar e tornam inesquecível o escritor e sua obra. 
O estudo de Lobato estruturou-se a partir das pesquisas realizadas e do contexto contemporâneo do autor, visualizado em visita aos dois sítios em que residiu. As atividades propostas aos acadêmicos são veiculadas em fóruns e debatidas no Skype, chats e redes sociais: criação e veiculação de vídeos na plataforma sobre as experiências pessoais com a leitura de Lobato; Fórum Personagem (série televisiva Sítio do Picapau Amarelo em suas duas versões; discografia do Programa com músicas alusivas a cada personagem; criação de apresentação de personagem a partir da obra literária, televisiva e musical); Fórum Lobato (Visita virtual ao Museu de Monteiro Lobato; estudo vida e obra do autor); Sessões no Skype; Leitura e debate (conto Negrinha; Lobato e a polêmica sobre racismo) entre outras propostas de atividades a partir da obra literária do autor disponibilizada na plataforma.

A elaboração individual do projeto é compartilhada com todos nos fóruns e a experiência de cada participante agrega qualidade ao que é produzido, permitindo reformulação até o momento da aplicação. Em 2018, o projeto está em fase de atividades com o autor, mas certamente vai ter importante impacto nas suas comunidades em razão da formação do grupo atual.

É possível prever um resultado positivo a ser alcançado, em razão da adesão de um número significativo de estudantes universitários e profissionais, não só de Letras, a um projeto novo que privilegia a leitura literária. A escolha do autor, por si só, já garante um espectro cultural rico, pois o autor é referência nacional em literatura infantojuvenil. Os participantes, por sua vez, contribuirão com sua produção e a de seu grupo de leitores através de projetos de literatura, relatos, fotografias, vídeos, releituras, clips, book trailers ou quaisquer formas de leitura de obras do autor que possam ser disponibilizadas na web, atuando como multiplicadores em suas comunidades, pois serão mediadores do programa em seus grupos de trabalho.

\section{CONSIDERAÇÕES FINAIS}

Leitura em rede é um projeto extensionista inédito na modalidade em que se insere educação a distância. Programa de leitura virtual pioneiro no país, integra a universidade às produções culturais das comunidades agregando o universo de Monteiro Lobato ao mundo hiperconectado da juventude contemporânea.

A Universidade Luterana do Brasil (campus Canoas e nas unidades envolvidas) é o espaço virtual e presencial de encontro do programa: o suporte para informações, acervo e encontros com profissionais está sediado na universidade ou nos seus polos. Assim, os participantes e seu grupo de estudo irão visualizar na universidade a imagem 
do projeto Leitura em rede, em um processo de aprendizagem em que serão agentes e sujeitos. Segundo Jon Dron (2015, p. 249), "não é suficiente que as tecnologias mudem para que ocorra mudança na educação a distância. Essas tecnologias devem ser utilizadas, integradas e absorvidas no sistema educacional".

O que une todos os aspectos da mudança é o processo de aprendizagem. Aprender é mudar, e as mudanças provocadas e forjadas na educação a distância são, em geral, praticamente todas manifestações de aprendizagem: um processo de crescimento que incorpora conhecimento anterior e constrói sobre ele para criar novos conhecimentos. DRON, 2015, p.269

\section{REFERÊNCIAS}

DRON, Jon. Inovação e mudança: mudando como mudamos. Trad. de Jarrilson da Silva Alves Costa. In: ZAWACKI-RICHTER, Olaf; ANDERSON, Terry (Orgs) Educação a Distância on line. São Paulo: ABED, 2015. p. 243 - 273

FOUCAMBERT, Jean. A leitura em questão. Porto Alegre: ArtMed, 1994.

GOUVÊA, Maria Cristina Soares. A literatura infantil e o pó de pirlimpimpim. In: LOPES, Eliane Marta Teixeira; GOUVÊA, Maria Cristina Soares (Orgs). Lendo e escrevendo Lobato. Belo Horizonte: Autêntica, 1999.

[1] FOUCAMBERT, Jean. A leitura em questão.Porto Alegre: ArtMed, 1994. p. 56

[2] CUNHA, Maria Antonieta. Comentário inserido na sobrecapa da obra Lendo e escrevendo Lobato, publicado em 1999 pela editora Autêntica.

[3] Ambos os sítios abrigam casas onde Lobato morou e há polêmicas em torno da exploração turística dos locais e da veracidade das informações em torno de seu lugar de nascimento. O sítio de Taubaté tem investimento e abriga um museu, enquanto a exfazenda Buquira (onde ele morou com a esposa e filhos de 1911 a 1917), embora seja apregoada como fonte de inspiração para as histórias de Emília, tem conservação precária e investimento cultural deficiente. 